\title{
Interactions between disturbance and dispersal reduce persistence thresholds in a benthic community
}

\author{
Carolyn J. Lundquist*, Simon F. Thrush, Giovanni Coco, Judi E. Hewitt
}

National Institute of Water and Atmospheric Research, PO Box 11-115, Hamilton 3251, New Zealand

\begin{abstract}
Interactions between the scale of dispersal and the disturbance regime can lead to radical shifts in the ability of organisms to colonize patches and persist within a landscape. We varied the spatial and temporal rates of disturbance and the connectivity between patches in a model of a patch landscape to illustrate thresholds of community persistence for a marine benthic community. We used model parameters representative of a New Zealand marine biogenic-structured community for which recovery after the cessation of disturbance has been observed within $\sim 15 \mathrm{yr}$. Model results suggest functional extinction of these biogenic communities under many disturbance regimes, and homogenization of the landscape to a community dominated by opportunistic species. Dispersal limitation increases in importance for recovery as the disturbance regime strengthens, indicating thresholds in the tolerable disturbance regime based on the dispersal potential of the dominant biogenic species. Limited sensitivity of our model results to different functional forms of the recovery trajectory and colonization neighborhood suggest that these results can be extrapolated to other biogenic structuredominated communities with recovery rates of a similar order of magnitude. Our results demonstrate that the scale of the disturbance regime and dispersal processes are fundamentally coupled, and knowing the scales of both processes is imperative when predicting change in the structure and diversity of benthic communities threatened by cumulative change.
\end{abstract}

KEY WORDS: Disturbance $\cdot$ Colonization $\cdot$ Dispersal $\cdot$ Connectivity $\cdot$ Landscape $\cdot$ Spatially explicit model $\cdot$ Patch dynamic $\cdot$ Thresholds $\cdot$ Resilience $\cdot$ Persistence

\section{INTRODUCTION}

All marine benthic communities consist of mosaics of patches with different histories of disturbance, colonization, and succession (Johnson 1970, Pearson \& Rosenberg 1978, Rhoads et al. 1978, Paine \& Levin 1981, Pickett \& White 1985, Hall 1994, Zajac 2008). In these communities, dispersal between patches will influence recovery and landscape-scale responses to changes in the disturbance regime (Palmer et al. 1996, Whitlatch et al. 1998, Thrush \& Whitlatch 2001, Pascual \& Guichard 2005). It is clear that marine landscapes are highly diverse, with high spatial variability, and abundant biogenic structures produced by both epifauna and infauna (Ellingsen et al. 2007). Even on the vast continental shelf and slope, small-scale heterogeneity is extensive and there is no evidence for panmixia (Levin et al. 2001, Levin \& Dayton 2009). Given the lack of general information on marine ecological dynamics as compared to terrestrial systems, the question arises as to whether we can use limited natural history information to populate landscape models to assist in ecosystem-based management of marine landscapes (Thrush \& Whitlatch 2001, Jennings et al. 2005, Kaiser et al. 2006).

Both natural and anthropogenic disturbances have the potential to result in habitat fragmentation and long-term degradative change in marine systems (Paine \& Levin 1981). Natural disturbances to the seafloor range from large and relatively infrequent events, 
e.g. large storms and hurricanes (Connell 1978) to small, frequent disturbances, e.g. ray foraging pits and wave disturbances (Sousa 1984, Thrush et al. 1991). In contrast, anthropogenic disturbances by benthic fishing gear, eutrophication, and sedimentation are often widespread and frequent relative to natural disturbances in the marine environment (Turner et al. 1999, Thrush \& Dayton 2002). Examples include estimates of as much as $20 \%$ of the New Zealand continental shelf trawled each year (Cryer et al. 2002) and the entire shelf off northern California trawled between 1.5 and 3 times per year (Friedlander et al. 1999). The general pattern, repeated across broad spatial scales, is that high rates of disturbance reduce the abundance of structure-forming species, resulting in homogeneous, simple, low diversity communities, and the loss of large and long-lived sedentary species that have disproportionately high contributions to ecosystem function (Dayton et al. 1995, Scheffer et al. 2001, Thrush et al. 2001, Thrush \& Dayton 2002).

Our understanding of resilience to disturbance in marine systems is limited (Thrush et al. 2009). Here we define resilience following Suding \& Hobbs (2009) as the amount of disturbance a system can endure while retaining the same ecological structure, function and feedbacks. After disturbance results in the clearing of a patch in a marine system, it is often unsuitable for immediate colonization by the dominant structureforming species (Wilcox et al. 2006, Zajac 2008). For example, marine structure-forming species in soft sediments such as corals, sponges, oysters, and bryozoans may require hard substrate such as shells for colonization (Hewitt et al. 2005). While the exact nature and prevalence of successional processes is still debated (Zajac 2001, Menge et al. 2005), time to recovery has both an element of life history of the dominant species, in terms of how long it takes to reach maturity and the organism's dispersal ability, and elements of community interactions such as competition and facilitation. Though the particular species and interactions vary between marine communities, increases in complexity of habitat structure (both infaunal and epifaunal), biogeochemical processes, and species interactions with time from disturbance are common to most marine systems (Pearson \& Rosenberg 1978, Rhoads et al. 1978, Hall 1994, Newell et al. 1998, Zajac 2001), particularly in soft sediments. These similarities suggest that a conceptual model of a generalized recovery trajectory can advance our understanding of the role of disturbance on marine community dynamics (Fig. 1).
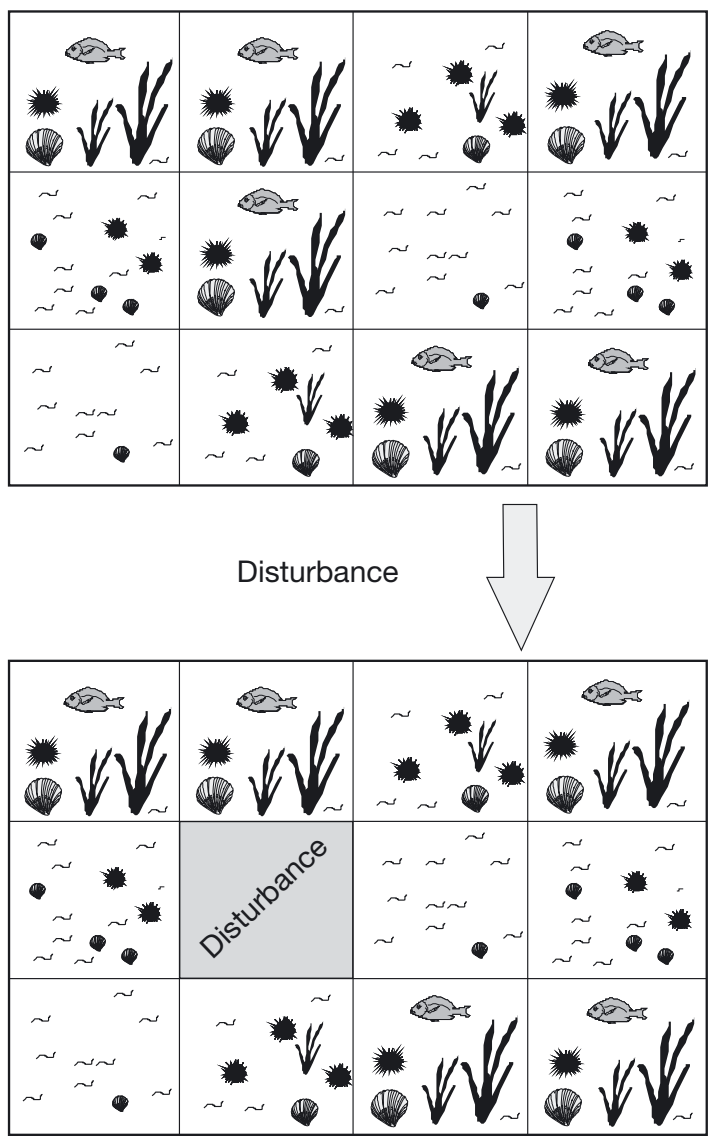

Recovery of biogenic reef community
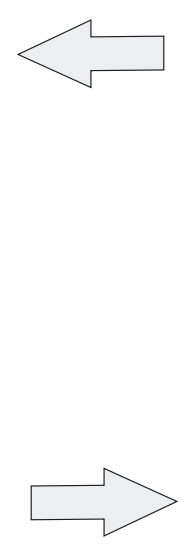

Colonization by opportunistic taxa and juvenile hard substrate taxa
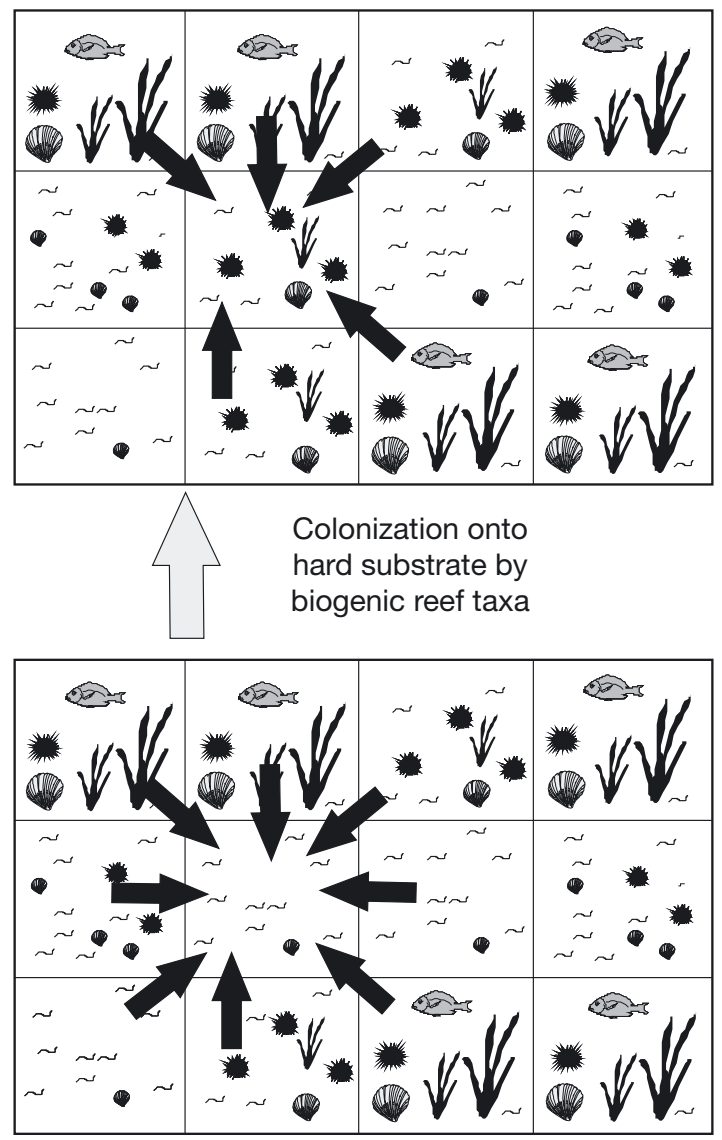

Fig. 1. Schematic of mosaic of biogenic habitat patches undergoing disturbance and recovery 
The likely time to recovery of impacted areas is also related to the magnitude of changes to the landscape (Rhoads et al. 1978, Thrush et al. 2008), such that recovery to a mature community becomes less likely as the disturbance size and frequency increase, reducing the abundance and proximity of potential colonists. Patches may also exhibit variability in their ability to serve as sources and sinks for colonization due to transport processes interacting with landscape features that modify the likelihood of successful colonization (Dias 1996, Pulliam 1996, Lundquist et al. 2004). Unfortunately, dispersal and colonization processes are one of the most poorly known aspects of marine ecosystems (Cowen \& Sponaugle 2009). The extent to which patch colonization is by local, regional, or global dispersers has large implications for community dynamics and resilience to disturbance (Palmer et al. 1996). While some species do have long-lived larvae and global dispersal potential, short-dispersing fauna and flora are also common, particularly in soft-sediment ecosystems (Grantham et al. 2003). In fact, reviews of larval dispersal suggest that sessile structural species such as sponges and corals generally have the lowest dispersal potential (Kinlan \& Gaines 2003).

To better manage marine systems, we must understand how the scale of connectivity and the temporal and spatial scales of disturbance (and resulting landscape fragmentation) interact as a framework for predicting the implications of more complex variability in colonization potential. Here we create a model to develop a general framework for disturbance and recovery dynamics in marine landscapes. We parameterize our model to represent the complex mosaic of biogenic habitat types typically found in marine benthic ecosystems, using rates from a well-observed system (Cranfield et al. 2003, Cranfield et al. 2004). A previous model of marine benthic landscapes, conceptually adapted from a successional model of forest disturbance (Turner et al. 1993), suggested temporal and spatial rates of disturbance at which benthic communities could persist, assuming no restrictions on colonist dispersal (Thrush et al. 2005). Our objective is to determine how incorporating restricted colonist dispersal decreases the range of spatial and temporal rates of disturbance under which benthic communities can persist. In effect, we demonstrate how the disturbance regime and dispersal processes interact to determine when complex mosaics of communities tip into states characterized by simple, homogeneous landscapes.

\section{METHODS}

Our spatially explicit patch dynamic model was created to illustrate the interaction of the disturbance regime and colonization processes in regulating community dynamics and landscape structure in marine benthic systems. Here, we consider a marine benthic community dominated in terms of habitat structure by relatively long-lived species that would typify bryozoan reefs, sponge gardens, bivalve beds, or other important biogenic features that have become increasing rare with increases in anthropogenic disturbance (Rothschild et al. 1994, Cranfield et al. 1999, Thrush \& Dayton 2002, Thrush et al. 2005). The landscape is modelled as a mosaic of habitat patches at varying ages from newly disturbed to mature structured habitat and thus represents a common perspective on benthic soft-sediment communities (Zajac 2008). We examine how the percent cover of mature biogenic habitat responds to varying spatial and temporal rates of disturbance and resulting levels of fragmentation (e.g. large solitary disturbances versus multiple smaller disturbances) within the landscape. We relate the percent cover of mature biogenic habitat to both thresholds in habitat dominance (disturbance combinations that result in percent cover by mature biogenic habitat of $>50 \%$ of the total landscape), and thresholds of functional extinction (disturbance combinations that result in percent cover by mature biogenic habitat of $<10 \%$ of the total landscape). We further define persistence thresholds as those disturbance rates below which mature biogenic habitat is not retained in the model landscape. Rates of recovery after fishing disturbance have varied with distance from and size of neighboring patches (Cranfield et al. 2003, 2004) suggesting that local dispersal between patches is important in determining patch recovery. Spatially-explicit dispersal is incorporated into the model by varying the size of the local neighborhood around disturbed cells from which colonists could be sourced.

We first describe our standard model structure and the parameters used to define disturbance and recovery processes based on a New Zealand marine benthic community dominated by biogenic structure-forming species. This standard model simulates landscapes with unrestricted colonization, and assumes no spatial dependence of colonization on proximity to occupied or mature habitat to represent an open system of interacting disturbed and recovering patches. Within this standard model structure, we vary spatial and temporal rates of disturbance to predict disturbance scenarios under which a large proportion of the landscape (e.g. $50 \%$ ) is dominated by mature benthic communities, and disturbance scenarios under which we predict functional extinction, i.e. $<10 \%$ of the landscape is dominated by mature benthic communities. We then modify this standard model to incorporate spatial restrictions in colonization to represent a system of patches with differing connectivities, repeating all dis- 
turbance combinations for twelve colonization scenarios that vary in the size of the surrounding neighborhood that serves as a colonist source for each cell. Finally, we test the sensitivity of model results to different realizations of the successional recovery process, and the neighborhood and age-dependent rules for source populations that govern colonization of disturbed cells.

Biogenic reef community. We developed a general model of community dynamics based on observed recovery rates for a well-studied biogenic reef community, a New Zealand shallow (depth $<100 \mathrm{~m}$ ) bryozoan reef community (Cranfield et al. 1999, 2003, 2004) (Table 1). Similar community dynamics and recovery rates occur for other biogenic reef communities, e.g. Chesapeake Bay oyster reefs (Rothschild et al. 1994, Lenihan 1999). The mature stage is defined by biogenic habitat attributes, and time to recovery from disturbance of this biogenic reef was estimated at $15 \mathrm{yr}$, at least in terms of the growth to reproductive stage of the habitat dominant species. Field observations show disturbed patches to typically progress through a series of successional stages of increasing habitat structure (Pearson \& Rosenberg 1978, Rhoads et al. 1978, Cranfield et al. 2004, Zajac 2008) (Table 1, Fig. 1). In the system we are modelling (dominated by epifaunal habitat architects), initial colonization is by opportunistic infaunal taxa such as small polychaetes or amphipods. This pioneer stage is followed by colonization of hard substrate forming species such as juveniles of large suspension feeding bivalves. Once these hard substrate fauna have matured, colonization onto hard sub-

Table 1. Recovery dynamics of biogenic reef communities in a conceptual model of community stages. Age: age of cell in model

\begin{tabular}{|c|c|}
\hline Age (yr) & Examples \\
\hline \multicolumn{2}{|l|}{ Pioneer } \\
\hline 1 & Small polychaetes and amphipods \\
\hline \multicolumn{2}{|c|}{ Juvenile hard substrate } \\
\hline $2-5$ & $\begin{array}{l}\text { Colonization by hard-substrate forming species: } \\
\text { large suspension feeding bivalves, juvenile } \\
\text { burrowing crustaceans, juvenile sponges, large } \\
\text { crustaceans }\end{array}$ \\
\hline \multicolumn{2}{|c|}{ Mature hard substrate } \\
\hline $6-14$ & $\begin{array}{l}\text { Mature stage of adult bivalves and encrusting } \\
\text { fauna (sponges, hydroids, tunicates), large } \\
\text { burrowing species and other species affiliated } \\
\text { with habitat structure, deep burrows, and } \\
\text { bioturbation. Colonization onto hard substrate } \\
\text { by juveniles of dominant mature biogenic reef } \\
\text { fauna: erect bryozoans and sponges }\end{array}$ \\
\hline \multicolumn{2}{|c|}{ Mature biogenic reef } \\
\hline $15+$ & $\begin{array}{l}\text { Mature bryozoans forming complex biogenic } \\
\text { reef }\end{array}$ \\
\hline
\end{tabular}

strate and then growth of dominant biogenic reef fauna occurs; without presence of these hard substrates, biogenic reef fauna do not colonize the surrounding soft sediments (Table 1 ).

While we conceptually define the recovery trajectory as representative of different successional stages that increase sequentially with time, in effect the model recovery trajectory includes only a time to recovery of a mature biogenic community. Our designation of different successional stages is implicit, but not an essential part of the model structure. We recognize that ecological interactions (e.g. priority effects, inter- and intraspecific competition, facilitation) can influence the trajectory of communities over time, both in terms of the temporal scale of recovery and the endpoint community that is attained (Farrell 1991, Tanner et al. 1996, Dudgeon \& Petraitis 2001, Menge et al. 2005). Later, we test sensitivity of model predictions to different realizations of the recovery trajectory (see 'Methods-Model sensitivity'), though still assuming the same endpoint biogenic community, allowing us to generalize across some potential ecological interactions that can change the temporal scale and magnitude of recovery.

Standard model structure. The model consists of a $100 \times 100$ cell grid, with each of the 10000 cells representing a habitat patch at a certain age. Conceptually, each cell represents a large enough area to sustain a biogenic reef community, and be reproductively successful such that the cell can serve as a colonist source to other cells. While the model is scale invariant, we conceptualize each grid cell to represent an area of $\sim 100 \times 100 \mathrm{~m}$, a realistic patch size for this biogenic reef community that historically has occupied 100s of $\mathrm{km}^{2}$ (Cranfield et al. 2003). While dispersal distances for species in this biogenic reef community have not been explicitly quantified, differences in recovery rates of disturbed patches separated from source reefs by distances of $<5 \mathrm{~km}$ suggest that dispersal in the range of 1 to 20 cells ( $100 \mathrm{~m}$ to $2 \mathrm{~km}$ ) is a likely estimate for many of the dominant biogenic species (Cranfield et al. 2003, 2004).

The model was initialized with all cells representing a mature state. After a disturbance occurred, a disturbed cell was redesigated cell age 1 , representing a pioneer community of immediate post-disturbance state. Disturbances and corresponding source areas for colonization were simulated assuming periodic boundary conditions (e.g. a torus). The age of each undisturbed cell was sequentially increased after each time step (corresponding to years). In the standard model, recently disturbed pioneer cells (age 1) increased sequentially in age with no spatial restrictions on colonization. We simulated the proportion of patches at each age in the landscape over 300 time steps, which was sufficient time to eliminate transient dynamics due 
to the initialization of the cells. We use the mean proportion of patches at each age in the final 50 time steps ( $t=250$ to 300$)$ to compare between simulations.

Disturbance. Disturbances were randomized across the landscape in continuous square blocks of sizes representing different percentages of the landscape disturbed and at time steps corresponding to the frequency of disturbance. Disturbance rates ranged in spatial scale from 0 to $100 \%$ of the landscape disturbed in each time step, and in temporal scale from 0 to 20 individual disturbance events per year. Disturbance frequencies $<1$ were accumulated over consecutive time steps (e.g. a frequency of 0.1 equates to 1 disturbance event once in $10 \mathrm{yr}$ ). Disturbances were created at random locations using a random number generator, and all cells were equally likely to be disturbed regardless of disturbance history. Simulations using different values of the seed for the random generator showed variation of $<1 \%$ in mean proportion of mature cells after 300 time steps; thus results using only 1 seed are presented here. Disturbed cells were reduced to pioneer stage 1, representing homogenization of habitat within the entire cell, such that no mature individuals remain to supply colonists to disturbed cells. While different types of disturbance (natural and anthropogenic) occur in most ecological systems, for simplicity we assume that only 1 type of disturbance is operating at the scale of the model, rather than disturbances with different frequencies and spatial extents operating concurrently.

Patch colonization. To examine how restricted colonization processes interact with the level of landscape fragmentation created by each of the disturbance scenarios, we added spatial restrictions on colonization to the standard model structure, limiting colonization of disturbed cells to those within a minimum distance to a colonist source. Colonization of a previously disturbed cell (age 1) occurred if there was at least 1 cell within the cell's neighborhood equal to or greater than the required source age. The neighborhood of each cell was defined by all surrounding cells within a particular dispersal distance ( $\mathrm{dd}$, number of cells from center). Dispersal distances thus corresponded to square neighborhoods centered on each cell of side length $(2 d d+1)$ and neighborhood area of $\left[(2 d d+1)^{2}-1\right]$. The source age was defined as age 6, representing the presence of mature hard structure-forming species that could serve as source populations for the initial colonization of disturbed cells. We simulated 12 dispersal distances $(1,2,3,4,5,6,7,8,9,10,15,20)$, with corresponding neighborhoods covering $0.08,0.24,0.48$, $0.80,1.20,1.68,2.24,2.88,3.60,4.40,9.60$, and $16.80 \%$ of the total landscape, respectively. We repeated the full set of disturbance combinations (spatial scale: 0 to $100 \%$, temporal scale: 0 to 20 events per year) for each dispersal distance. We examined spatially dependent colonization of only pioneer (i.e. recently disturbed) cells, though similar restrictions with aging of 'older' patches dependent on proximity to source patches showed qualitatively similar results as the scale of dispersal was varied (C. Lundquist unpubl. data).

Model sensitivity. Actual recovery trajectories and colonization dynamics with respect to the size and agestructure of colonist source populations are rarely quantified for marine benthic communities (though see Kaiser et al. 2006 for a review of community recovery rates after the cessation of fishing, and Ellis et al. 2008 for estimates of recovery rates for some benthic phyla). As these recovery rates have not been quantified for the biogenic reef community that we model here, we examine sensitivity of the model to different functional representations of the recovery trajectory and of the influence of patch neighborhood on colonization success. For example, it is unlikely that patch successional processes proceed linearly from one stage to the next (Johnson \& Miyanishi 2008); rather we expect that inter- and intraspecific interactions result in nonlinearities in the recovery of patches, as well as the potential for multiple endpoint communities (Farrell 1991, Dudgeon \& Petraitis 2001, Zajac 2001, Menge et al. 2005, Caplat \& Anand 2009). Similarly, we compared different realizations of dispersal and colonization processes that regulate the local abundance of colonists, e.g. whether recovery and/or colonization is dependent on the presence of a single neighbor or the successional status of the entire local neighborhood.

To analyze the sensitivity of landscape dynamics to the recovery trajectory, we varied the mathematical representation of recovery over time, and the relative dependence of recovery on neighborhood composition. Four recovery functions were used: (1) neighborhood-independent sequential function (the standard model structure); (2) neighborhood-dependent step function; (3) neighborhood-dependent linear increase; (4) neighborhood-dependent logistic increase (Fig. 2). In the neighborhood-independent recovery, cells were aged sequentially by 1 at each time step. For neighborhood-dependent cases, recovery functions were based on the proportion of occupied cells (cells of age $>1$ ) in each cell's neighborhood, based on the dispersal distance modeled in each simulation. We chose sensitivities in recovery based on variability of $50 \%$ of the standard (Type 1) sequential recovery rate. For the step function, cells increased in age by 0.5 (50\% less than baseline) if the percent occupied was $<20 \% ; 1$ if percent occupied was 20 to $50 \%$; and 1.5 (50\% higher than baseline) if percent occupied was $>50 \%$. The linear function had a minimum value of 0.5 with $0 \%$ occupancy and a high value of 1.5 with $100 \%$ occupancy within each cell's neighborhood. The logistic recovery curve used a sigmoid function fit to the same minimum and maximum values as the linear function. 


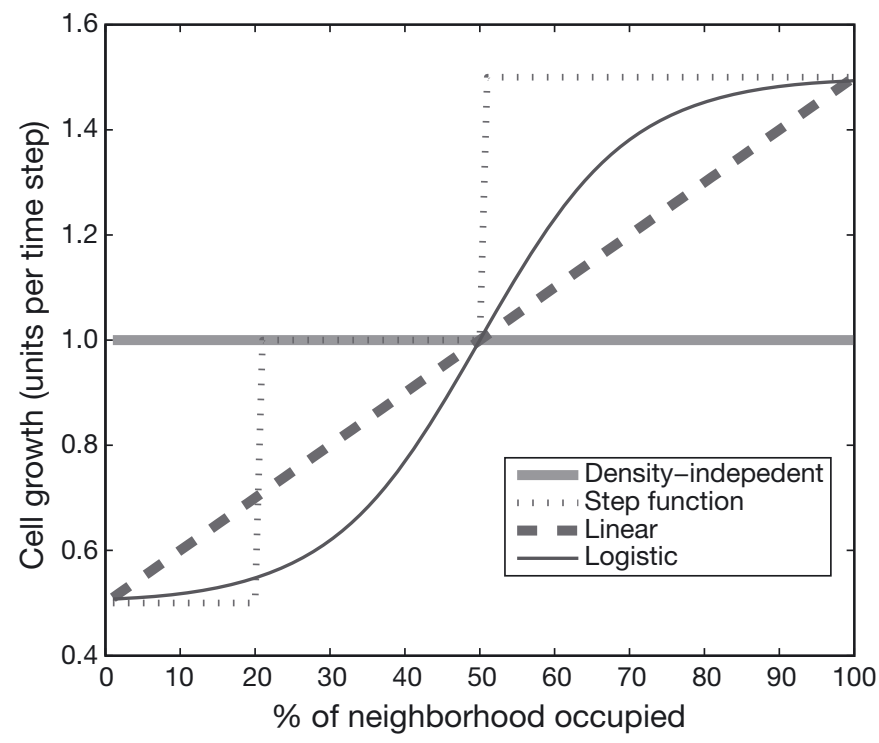

Fig. 2. Functional forms of recovery trajectory used in sensitivity analysis

To analyze the influence of different model realizations of the colonization neighborhood on modeled landscape dynamics, we compared 3 mathematical representations of cell colonization: (1) maximum cell age within neighborhood (the standard colonization option, described previously); (2) percentage of neighborhood occupied; and (3) percentage of neighborhood in mature state. For the first, colonization of a previously disturbed cell (age 1) occurred during that time step if a cell was within a minimum proximity to a colonist source, i.e. there was at least 1 cell within the cell's neighborhood equal to or greater than the required source age, with the standard colonization option being source age $=6$. Within this first sensitivity analysis, we also varied the minimum source age to further investigate the dependence of model results on the presence of neighboring mature biogenic or hardstructured habitat. We analyzed 2 additional colonist source ages, representing colonist age of a mature biogenic reef (source age $=15$ ), and of all non-disturbed cells being able to contribute to the colonist source pool (source age $=2$ ). For the second colonization scenario, colonization of a previously disturbed cell occurred during that time step if at least $20 \%$ of the neighborhood was occupied (age $>1$ ). For the third colonization scenario, colonization occurred if at least $20 \%$ of the neighborhood was in a mature community state (age 15 or greater). For the second and third colonization scenarios, the $20 \%$ metric was chosen based on representation of both an ecologically relevant amount of mature biogenic reef habitat, and not being overly restrictive in requirements of mature habitat (e.g. many combinations of disturbance rate did not result in $>50 \%$ mature habitat remaining).

\section{RESULTS}

Our model results showed one of 2 patterns in community dynamics for each individual simulation. Simulations either reached a relatively steady proportion of cells in each successional stage, or simulations reduced to a homogeneous $100 \%$ pioneer stage over the course of the simulation. Ecologically, we interpret dominance by the pioneer stage as the degradation of the benthic community mosaic into a landscape lacking the heterogeneity generated by long-lived, biogenic habitatforming species.

For simulations that result in the first pattern of a stable stage distribution (and that did not result in extinction of the mature habitat-forming communities), the combinations of spatial and temporal frequencies of disturbance were surprisingly restricted, even for simulations with no spatial restrictions on colonization. Contour plots of combinations of spatial and temporal rates of disturbance that resulted in 50 and $10 \%$ mature habitat illustrate further reductions in the domain of suitable disturbance regimes when comparing the standard model results to scenarios with restricted colonization, and as the size of the colonist neighborhood (dispersal distance) was decreased (Fig. 3).

To examine changes in thresholds of persistence of mature habitat, we plotted changes in mature and occupied habitats for constant disturbance frequencies of 1 disturbance event per year, while varying the spatial extent of disturbance (Fig. 4). We define persistence thresholds as combinations of the spatial extent and frequency of disturbance where the percentage of mature (or occupied) habitat becomes zero. Simulations with local dispersal $(\mathrm{dd}=1$ ) show persistence thresholds at $<10 \%$ of the landscape disturbed per year. As colonist source neighborhoods increase to include regional neighbors, no decrease from maximum possible occupied habitat is shown until disturbance rates of $>20 \%$ per year, with thresholds of persistence of occupied habitat increasing to $\sim 35 \%$ with the largest dispersal distance simulated ( $\mathrm{dd}=20$ ) (Fig. 4). In comparison to the unrestricted dispersal scenarios, the percent mature curve is nearly identical to the ' $\mathrm{dd}=20$ ' scenario, while percent occupied for the unrestricted dispersal scenarios is represented by the $45^{\circ}$ line, i.e. the $45^{\circ}$ line represents $(1-$ the total disturbance rate) per time step. Thus, even regional dispersal simulations that assume minimal spatial restrictions on dispersal demonstrate significant declines from the maximum possible occupied and mature habitat.

To examine thresholds in persistence, functional extinction and dominance, we compared simulations that varied colonist neighborhoods (Fig. 5). As results for unrestricted simulations were visually similar to the 
' $\mathrm{dd}=20$ ' scenarios at the resolution presented here, we present only the ' $\mathrm{dd}=20$ ' scenario. Relative changes in the percentage of occupied habitat were larger than those changes in the percentage of mature habitat as the size of the colonist neighborhood was increased for most disturbance combinations (Fig. 5). These results illustrate combinations of spatial and temporal rates of disturbance at which mature biogenic habitat are unlikely to persist, even with unrestricted dispersal. The range of 'successful' combinations of spatial and temporal disturbance frequency (i.e. resulting in nonzero cover of mature or occupied habitat) increased as colonist neighborhood increased (Fig. 5).

Sensitivity analyses demonstrate the importance of connectivity in interpreting disturbance/recovery processes, with simulations that modelled restricted dispersal being more sensitive to differences between mathematical representations of intrinsic patch dynamics (Fig. 6). Model results showed minimal
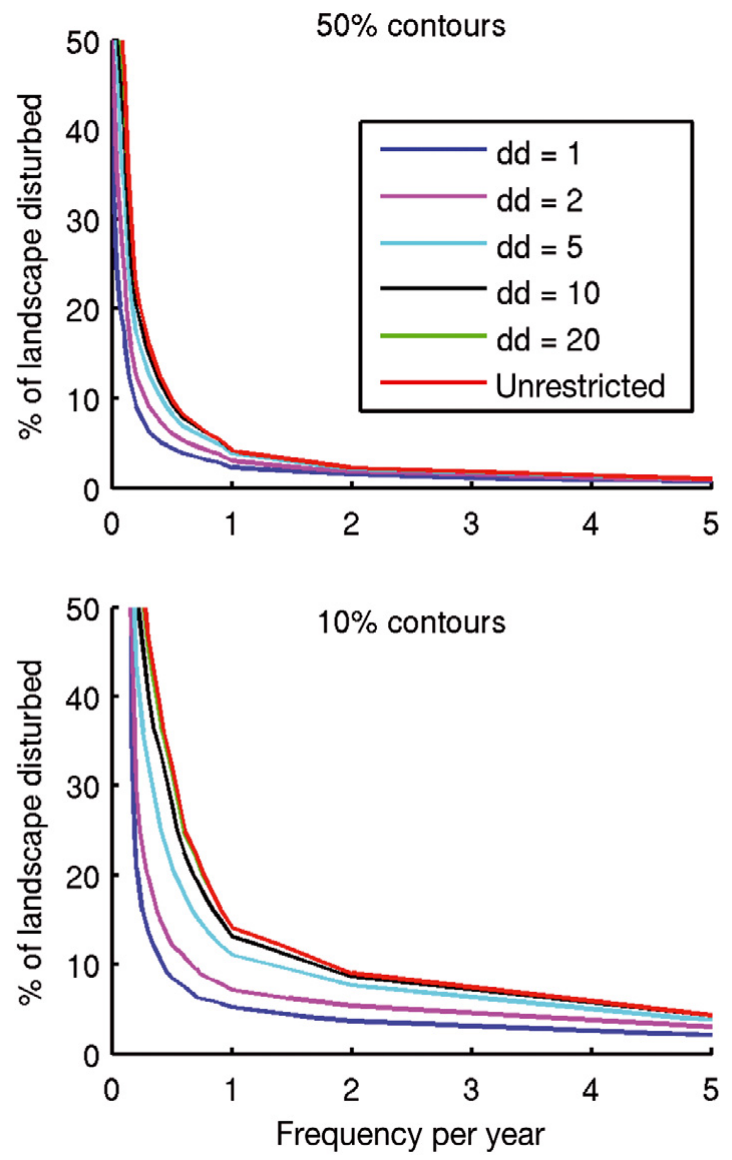

Fig. 3. Contour plots of 50 and $10 \%$ of the landscape maintained in mature habitat across the range of spatial and temporal scales of disturbance. Results are based on the standard model options for recovery (sequential) and colonization (max. age of cells within neighbor, source age $=6 \mathrm{yr}$ ). Contours are shown for dispersal distances $(\mathrm{dd})=1,2,5,10$, and 20 cells, and for the standard model with unrestricted colonization. Note the overlap of contours for $\mathrm{dd}=20$ and the unrestricted dispersal scenarios sensitivity to functional form of the recovery (successional) trajectory, with $<10 \%$ variability in the percent of mature habitat between the 4 functional forms simulated, illustrated for 3 colonist neighborhoods (Fig. 6a). In all cases, the step function showed a slightly larger percentage of mature habitat (Fig. 6a). Sensitivity to source age was more apparent in simulations with localized dispersal than in less restricted dispersal simulations (Fig. 6b). Simulations with restricted dispersal showed largest decreases in mature habitat when source colonists were restricted to mature habitat (source age 15), and less severe decreases when source colonists were restricted to hard structure habitat (source age 6 , the standard case), relative to simulations where colonist sources included all undisturbed cells (source age 2) (Fig. 6b). Finally, sensitivity to colonization rule was minimal for less restricted dispersal scenarios, but showed large decreases in percent
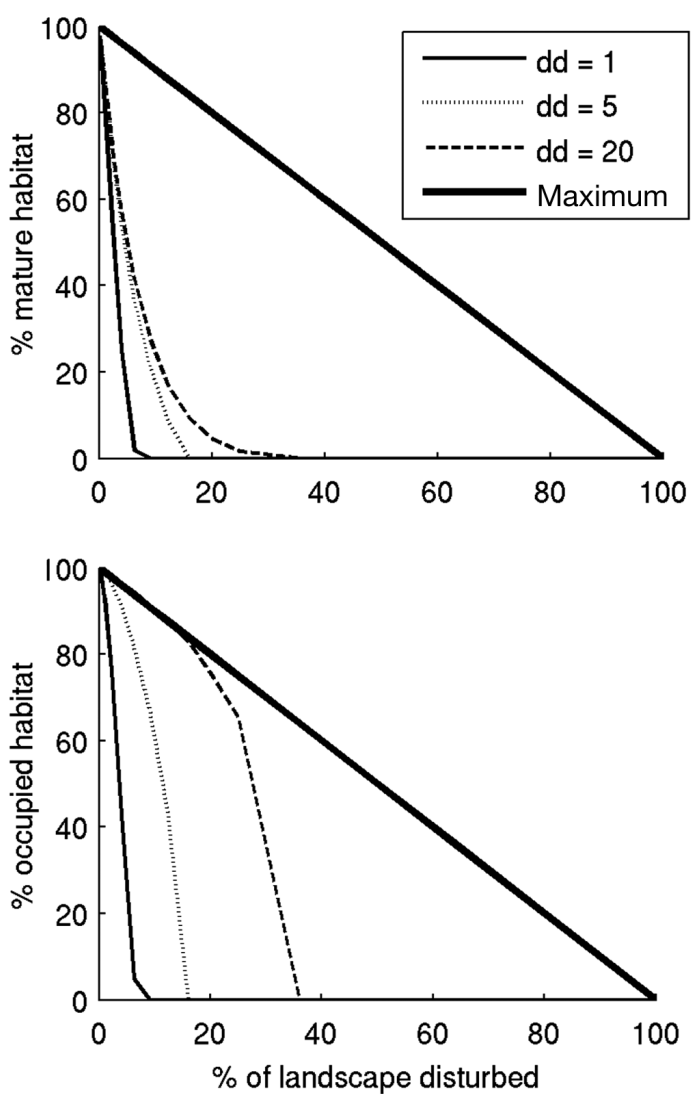

Fig. 4. Comparison of (a) \% mature and (b) \% occupied habitat for simulations with constant frequency of 1 disturbance $\mathrm{yr}^{-1}$, and varying spatial extent of disturbance, for 3 sizes of colonist neighborhood (1, 5, and 20 cell dispersal distances). Thick line symbolizes max. possible \% of occupied or mature cells for each disturbance rate (e.g. max. occupied habitat for simulations with a disturbance rate of $20 \%$ of the landscape $\mathrm{yr}^{-1}$ is $80 \%$ ). Results are based on standard model options for recovery (sequential) and colonization (max. age of cells within neighborhood, source age $=6 \mathrm{yr}$ ) 


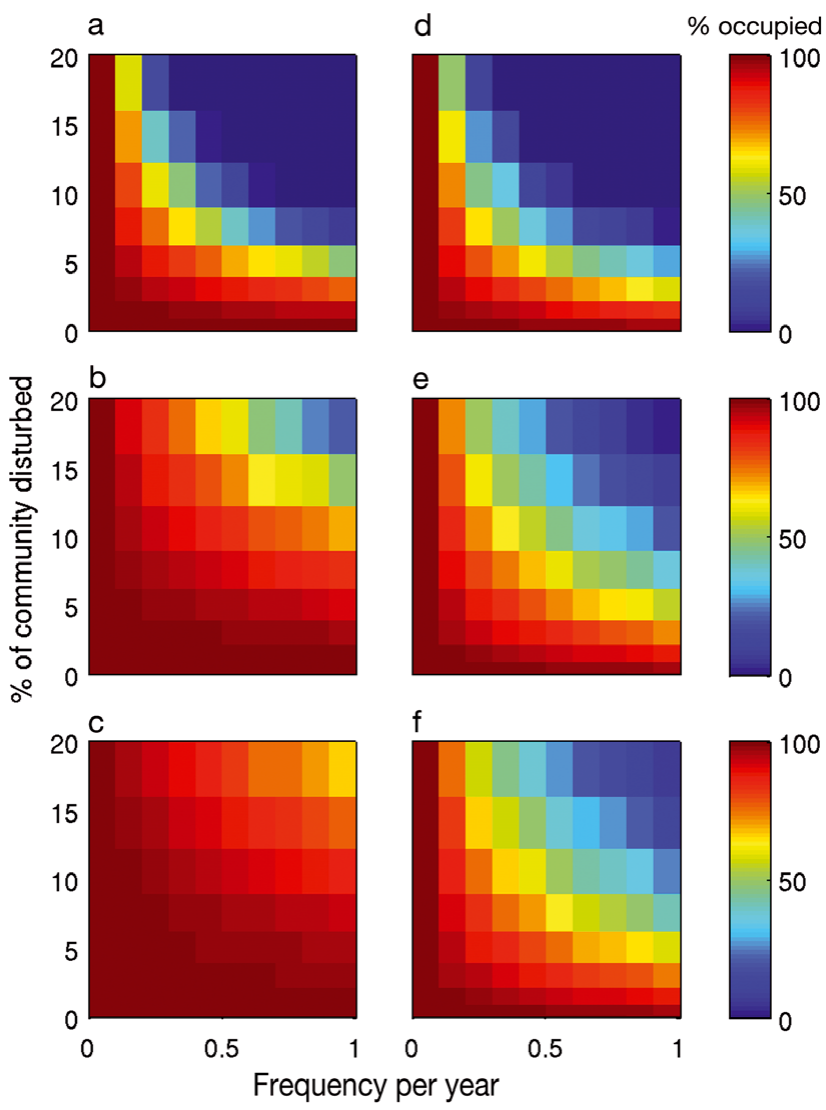

Fig. 5. Contour plots of the percentages of occupied $(a, b, c)$ and mature biogenic habitat remaining $(d, e, f)$ for different combinations of temporal frequency and spatial extent of disturbance, illustrated for dispersal distance $=1(\mathrm{a}, \mathrm{d})$; dispersal distance $=5(\mathrm{~b}, \mathrm{e})$; and dispersal distance $=10$ cells $(\mathrm{c}, \mathrm{f})$. Results are based on the standard model options for recovery (sequential) and colonization (max. age of cells within neighbour, source age $=6 \mathrm{yr}$ ). Red shading indicates persistence of occupied (or mature) habitat under that disturbance combination, while blue shading indicates that occupied (or mature) habitat is unlikely to persist under that disturbance combination

mature for localized dispersal scenarios for colonization rules where colonization was dependent on presence of at least $20 \%$ mature habitat (Fig. 6c). Simulations with $20 \%$ occupied rules and maximum age rules showed similar results.

\section{DISCUSSION}

The resilience of communities dominated by large, long-lived species is threatened by increasing disturbance rates (Scheffer et al. 2001, Thrush \& Dayton 2002, Bremner et al. 2005, Thrush et al. 2006). Disturbance fragments the landscape, reducing both the proportion and proximity of mature habitat that provides colonists (With \& King 1999). Feedbacks between disturbance regimes and dispersal and coloniza-
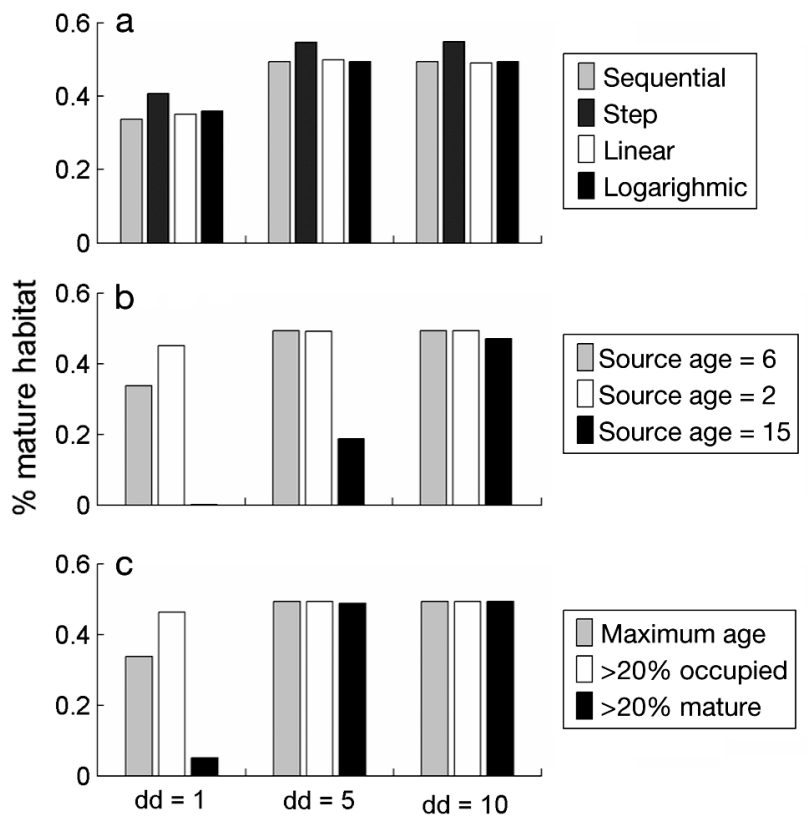

Fig. 6. Sensitivity to model parameters, illustrated for \% mature habitat for colonist neighborhoods of dispersal distances of 1, 5, and 10 cells. (a) Functional form of recovery (standard option-sequential; step; linear; logarithmic); (b) source age for colonization based on max. neighbor age (standard option- source age $=6$; source age $=2$; source age $=15 \mathrm{yr}$ ); and (c) colonization rule (standard option-max. neighbor age with source age $=6 \mathrm{yr}_{i}>20 \%$ occupied $_{i}>20 \%$ mature). All simulations illustrated using disturbance rate of 5 disturbances each of $1 \%$ of total landscape $\mathrm{yr}^{-1}$

tion processes underlie changes to resilience (Pascual \& Guichard 2005, Thrush et al. 2009). Here, we highlight a feedback mechanism between landscape connectivity and fragmentation by disturbance that further reduced the cover of mature biogenic habitat. This result is in part due to the contribution of time-dependent colonization processes on community recovery such that disturbance rates are too high for patches to recover to the minimum age and thus serve as a colonist source (Ellner \& Fussmann 2003). Here, our model illustrates a persistence threshold, dependent on the particular connectivity matrix that declines faster than would be predicted from the disturbance rate alone.

As mature stages of many marine biogenic communities exhibit restricted dispersal (Osman \& Whitlatch 1998, Kinlan \& Gaines 2003), our results indicate that thresholds in community persistence will be exceeded at lower disturbance rates for these biogenic-structured communities. As colonist source neighborhoods were decreased in the model scenarios to represent more restricted dispersal indicative of these biogenic communities, the domain of disturbance rate resulting in functional extinction of biogenic structured habitat increased. Other landscape models have demonstrated interactions between dispersal and patch dynamics, 
such that the total abundance of habitat or spatial configuration often determines habitat thresholds below which dispersal behavior has a strong influence on community dynamics (With \& Crist 1995, Wiens et al. 1997, With et al. 1997, Flather \& Bevers 2002, Johst et al. 2002, With \& King 2004). Similarly, metapopulation and metacommunity models emphasize the need to consider both the relative influence of regional versus local processes and intrinsic patch dynamics to predict extinction risk (Loreau \& Mouquet 1999, Loreau et al. 2003, Cardinale et al. 2004, Kallimanis et al. 2005, Laird \& Schamp 2008). Field experiments highlight a variety of processes influencing recovery that often involve interactions between dispersal and intrinsic process in a scale-dependent fashion, for example, edge effects (terHorst \& Dudgeon 2009); habitat stability (Thrush et al. 1996); and the response of opportunistic species (Norkko et al. 2006). As dispersal behavior, the scale of dispersal, and the relative contribution of local versus regional colonist sources are often poorly known, understanding that large, long-lived communities will be more strongly affected by increasing rates of disturbance improves our ability to predict resilience of communities under increasing rates of anthropogenic disturbance (Thrush et al. 2006, 2009).

Our results support numerous theoretical and empirical demonstrations of the importance of habitat structure for ecosystem function of marine benthic communities (Turner et al. 1999, Thrush et al. 2001, Diaz et al. 2003). Relevant processes dependent on structural attributes include age-dependence to arrive at mature biogenic structured communities and a dependence on the existence of mature structured communities for colonization to occur (Scheffer et al. 2001, Ellner \& Fussmann 2003). Unfortunately, the importance of habitat structure and associated successional processes required for biogenic habitats to be created are often ignored in theoretical models of metapopulations and metacommunities (Wilcox et al. 2006).

Our model simulations encompassed many realistic rates of natural and anthropogenic disturbance, so the large range of solutions that represented functional extinction of biogenic reef communities was unexpected. High intensity disturbances are likely to be unsustainable for complex, biogenic-structured communities dominated by long-lived and poor dispersing species. The potential for historical anthropogenic disturbance rates to have tripped thresholds for persistence of these biogenic communities is likely to contribute to the problem of demonstrating differences between control and fished areas in some locations subject to trawling (Dayton et al. 1995, Daan et al. 2005, de Juan et al. 2007). In addition, our model demonstrates inequalities in the influence of spatial and temporal disturbance on landscape dynamics, such that results differed between simulations with the same total annual disturbance rate, but different spatial and temporal combinations of disturbance (i.e. $10 \%$ disturbed once per year versus $1 \%$ disturbed 10 times per year). These results imply that the rate of disturbance has a much more complex interaction with successional processes via habitat connectivity, and the configuration and fragmentation of the landscape resulting from the particular disturbance regime.

Our model incorporated many simplifying assumptions that in most cases make our results a conservative estimate of the impacts of disturbance on marine landscapes. For example, we assumed no spatial correlation in disturbance, though most marine disturbances are spatially correlated, e.g. trawling disturbance with aggregated distribution of trawl effort (Friedlander et al. 1999). Sedimentation events from terrestrial runoff also have a higher probability of impacting certain areas in estuaries and coastal zones, although impacts change considerably depending on wind and tidal conditions (Thrush et al. 2004). Similarly, fishing disturbances may exacerbate other processes (such as landbased increases in sedimentation or eutrophication) that otherwise decrease resilience to disturbance (Lenihan 1999, Crain et al. 2008). Natural disturbance rates are also expected to vary in size, with an '1/f noise' nature such that most disturbances are small and few are large (Pascual \& Levin 1999, Denny et al. 2004, Fisher et al. 2008), rather than the constant size/frequency of disturbance modelled in each simulation here. We speculate that impacts of correlated disturbances would depend strongly on connectivity within the landscape, and the relative proportion and configuration of the landscape that is left undisturbed (Kallimanis et al. 2005). In contrast, we predict that including concurrent disturbance impacts of different temporal and spatial scales (including that of multiple stressors) would have additive or multiplicative results on model predictions as the disturbance regime is increased (Crain et al. 2008). Finally, we simulated only 'square' disturbances; we predict that varying the shape of disturbances via configurations with larger perimeter to area ratios could interact with disturbance frequency to increase or decrease landscape fragmentation, depending on the size of the disturbance relative to the total area of the landscape, and thus modify the range of feasible disturbance regimes (Liddel 2001, Fonseca et al. 2004, Langmead \& Sheppard 2004).

Other assumptions are likely to have more variable effects. For example, we assumed that disturbances resulted in complete clearing of a cell such that no macro-organisms remain to facilitate colonization by pioneers. Organisms that escape the disturbance impact, e.g. juveniles that are left intact, or adults that are 
damaged but regenerate, could dampen threshold effects. Experimental manipulations in benthic systems have shown the importance of historical community presence in determining colonization after disturbance (Tanner et al. 1996, Dudgeon \& Petraitis 2001). We also assumed that there were no differences in dispersal rate between successional community stages, though it is likely that mature structural species will have lower dispersal rates than highly mobile pioneer species (Osman \& Whitlatch 1998, Grantham et al. 2003, Kinlan \& Gaines 2003). We also did not consider variations in suitability of each patch for colonization, although a number of processes will affect successful settlement, e.g. hydrodynamic forces, habitat selection, and settling behavior (Butman 1987). This may explain the small amount of change in community dynamics we observed after increasing the colonist source pool from $\sim 17 \%$ of the total landscape (corresponding to a radius of 20 cells out from a disturbed cell) to a global colonist neighborhood consisting of the entire landscape.

In general, our results show the importance of the degree of neighborhood connectivity in defining a community's ability to persist in the face of disturbance. These results can easily be extrapolated to a spatial management context for other biogenic-structured communities with similar times to recovery to determine relevant rates of disturbances that result in functional extinction (or alternatively, which rates result in a minimum proportion of mature community persisting across a landscape). Vice versa, we could utilize the observed proportion of various successional stages at a location to determine the likely disturbance rate or dispersal kernels. It is important to understand the response of sensitive biogenic habitats to disturbance-mediated changes in the connectivity of habitat patches, and the dependence of these habitats on proximity to colonist sources for resilience to and recovery from disturbance. Anthropogenic impacts are continually increasing, including impacts of climate change on coastal habitats (Harley et al. 2006), though the expected change in disturbance rates due to climate change is unknown. Our approach, linking connectivity and disturbance rates, can further aid in determining patterns of biodiversity, production, ecosystem function, and resilience across ecological scales (Leibold et al. 2004, Karlson 2006, Thrush et al. 2009).

Acknowledgements. We thank the New Zealand Foundation for Research Science and Technology (Project \#C01X0501) for financial support. We thank D. Lohrer and J. Leathwick for comments on the manuscript; J. Halliday for creating Fig. 1; and R. Gorman, S. Stephens, and K. Julian for assistance with programming.

\section{LITERATURE CITED}

Bremner JF, Chris LJ, Rogers SI (2005) Biological traits of the North Sea benthos: does fishing affect benthic ecosystem function? Am Fish Soc Symp 41:477-489

Butman CA (1987) Larval settlement of soft-sediment invertebrates: the spatial scales of pattern explained by active habitat selection and the emerging role of hydrodynamical processes. Oceanogr Mar Biol Annu Rev 25:113-165

Caplat P, Anand M (2009) Effects of disturbance frequency, species traits and resprouting on directional succession in an individual-based model of forest dynamics. J Ecol 97: 1028-1036

> Cardinale BJ, Ives AR, Inchausti P (2004) Effects of species diversity on the primary productivity of ecosystems: extending our spatial and temporal scales of inference. Oikos 104:437-450

Connell JH (1978) Diversity in tropical rain forests and coral reefs. Science 199:1302-1310

Cowen RK, Sponaugle S (2009) Larval dispersal and marine population connectivity. Annu Rev Mar Sci 1:443-466

> Crain CM, Kroeker K, Halpern BS (2008) Interactive and cumulative effects of multiple human stressors in marine systems. Ecol Lett 11:1304-1315

> Cranfield HJ, Michael KP, Doonan IJ (1999) Changes in the distribution of epifaunal reefs and oysters during 130 years of dredging for oysters in Foveaux Strait, southern New Zealand. Aquat Conserv: Mar Freshw Ecosyst 9:461-483

> Cranfield HJ, Manighetti B, Michael KP, Hill A (2003) Effects of oyster dredging on the distribution of bryozoan biogenic reefs and associated sediments in Foveaux Strait, southern New Zealand. Cont Shelf Res 23:1337-1357

Cranfield HJ, Rowden AA, Smith DJ, Gordon DP, Michael KP (2004) Macrofaunal assemblages of benthic habitat of different complexity and the proposition of a model of biogenic reef habitat regeneration in Foveaux Strait, New Zealand. J Sea Res 52:109-125

> Cryer M, Hartill B, O'Shea S (2002) Modification of marine benthos by trawling: toward a generalization for the deep ocean? Ecol Appl 12:1824-1839

> Daan N, Gislason H, Pope JG, Rice JC (2005) Changes in the North Sea fish community: evidence of indirect effects of fishing? ICES J Mar Sci 62:177-188

Dayton PK, Thrush SF, Agardy TM, Hofman RJ (1995) Environmental effects of fishing. Aquat Conserv: Mar Freshw Ecosyst 5:205-232

de Juan S, Thrush SF, Demestre M (2007) Functional changes as indicators of trawling disturbance on a benthic community located in a fishing ground (NW Mediterranean Sea). Mar Ecol Prog Ser 334:117-129

Denny MW, Helmuth B, Leonard GH, Harley CDG, Hunt LJH, Nelson EK (2004) Quantifying scale in ecology: lessons from a wave-swept shore. Ecol Monogr 74:513-532

> Dias PC (1996) Sources and sinks in population biology. Trends Ecol Evol 11:326-330

> Diaz RJ, Cutter GR, Able KW (2003) The importance of physical and biogenic structure to juvenile fishes on the shallow inner continental shelf. Estuaries 26:12-20

$>$ Dudgeon S, Petraitis PS (2001) Scale-dependent recruitment and divergence of intertidal communities. Ecology 82: 991-1006

Ellingsen KE, Hewitt JE, Thrush SF (2007) Rare species, habitat diversity and functional redundancy in marine benthos. J Sea Res 58:291-301

Ellis N, Pantus F, Welna A, Butler A (2008) Evaluating ecosystem-based management options: effects of trawling in Torres Strait, Australia. Cont Shelf Res 28:2324-2338 
Ellner SP, Fussmann G (2003) Effects of successional dynamics on metapopulation persistence. Ecology 84:882-889

Farrell TM (1991) Models and mechanisms of succession: an example from a rocky intertidal community. Ecol Monogr 61:95-113

Fisher JI, Hurtt GC, Thomas RQ, Chambers JQ (2008) Clustered disturbances lead to bias in large-scale estimates on forest sample plots. Ecol Lett 11:554-563

Flather $\mathrm{CH}$, Bevers M (2002) Patchy reaction-diffusion and population abundance: the relative importance of habitat amount and arrangement. Am Nat 159:40-56

Fonseca MS, Whitfield PE, Kenworthy WJ, Colby DR, Julius BE (2004) Use of two spatially explicit models to determine the effect of injury geometry on natural resource recovery. Aquat Conserv: Mar Freshw Ecosyst 14:281-298

Friedlander AM, Boehlert GW, Field ME, Mason JE, Gardner JV, Dartnell P (1999) Sidescan-sonar mapping of benthic trawl marks on the shelf and slope off Eureka, California. Fish Bull 97:786-801

> Grantham BA, Eckert GL, Shanks AL (2003) Dispersal potential of marine invertebrates in diverse habitats. Ecol Appl 13(Suppl):108-116

Hall SJ (1994) Physical disturbance and marine benthic communities: life in unconsolidated sediments. Oceanogr Mar Biol Annu Rev 32:179-239

Harley CDG, Hughes AR, Hultgren KM, Miner BG and others (2006) The impacts of climate change in coastal marine systems. Ecol Lett 9:228-241

Hewitt JE, Thrush SF, Halliday J, Duffy C (2005) The importance of small-scale habitat structure for maintaining beta diversity. Ecology 86:1619-1626

Jennings S, Freeman S, Parker R, Duplisea DE, Dinmore TA (2005) Ecosystem consequences of bottom fishing disturbance. Am Fish Soc Symp 41:73-90

Johnson RG (1970) Variations in diversity within benthic marine communities. Am Nat 104:285-300

Johnson EA, Miyanishi K (2008) Testing the assumptions of chronosequences in succession. Ecol Lett 11:419-431

> Johst K, Brandl R, Eber S (2002) Metapopulation persistence in dynamic landscapes: the role of dispersal distance. Oikos 98:263-270

Kaiser MJ, Clarke KR, Hinz H, Austen MCV, Somerfield PJ, Karakassis I (2006) Global analysis of response and recovery of benthic biota to fishing. Mar Ecol Prog Ser 311:1-14

Kallimanis AS, Kunin WE, Halley JM, Sgardelis SP (2005) Metapopulation extinction risk under spatially autocorrelated disturbance. Conserv Biol 19:534-546

Karlson RH (2006) Metapopulation dynamics and community ecology of marine systems. In: Kritzer JP, Sale PF (eds) Marine metapopulations. Elsevier, Maryland Heights, p $457-489$

Kinlan BP, Gaines SD (2003) Propagule dispersal in marine and terrestrial environments: a community perspective. Ecology 84:2007-2020

Laird RA, Schamp BS (2008) Does local competition increase the coexistence of species in intransitive networks? Ecology 89:237-247

Langmead O, Sheppard C (2004) Coral reef community dynamics and disturbance: a simulation model. Ecol Modell 175:271-290

Leibold MA, Holyoak M, Mouquet N, Amarasekare P and others (2004) The metacommunity approach: a framework for multi-scale community ecology. Ecol Lett 7:601-613

Lenihan HS (1999) Physical-biological coupling on oyster reefs: how habitat structure influences individual performance. Ecol Monogr 69:251-276
Levin LA, Dayton PK (2009) Ecological theory and continental margins: where shallow meets deep. Trends Ecol Evol 24:606-617

Levin LA, Etter RJ, Rex MA, Gooday AJ and others (2001) Environmental influences on regional deep-sea species diversity. Annu Rev Ecol Syst 32:51-93

> Liddel M (2001) A simple space competition model using stochastic and episodic disturbance. Ecol Modell 143:33-41

Loreau M, Mouquet N (1999) Immigration and the maintenance of local species diversity. Am Nat 154:427-440

> Loreau M, Mouquet N, Gonzalez A (2003) Biodiversity as spatial insurance in heterogeneous landscapes. Proc Natl Acad Sci USA 100:12765-12770

Lundquist CJ, Thrush SF, Oldman JW, Senior AK (2004) Limited transport and recolonization potential in shallow tidal estuaries. Limnol Oceanogr 49:386-395

Menge BA, Allison GW, Blanchette CA, Farrell TM, Olson AM, Turner TA, van Tamelen P (2005) Statis or kinesis: hidden dynamics of a rocky intertidal macrophyte mosaic revealed by a spatially explicit approach. J Exp Mar Biol Ecol 314:3-39

Newell RC, Seiderer LJ, Hitchcock DR (1998) The impact of dredging works in coastal waters: a review of the sensitivity to disturbance and subsequent recovery of biological resources on the sea bed. Oceanogr Mar Biol Annu Rev $36: 127-178$

Norkko A, Rosenberg R, Thrush SF, Whitlatch RB (2006) Scale- and intensity-dependent disturbance determines the magnitude of opportunistic response. J Exp Mar Biol Ecol 330:195-207

> Osman RW, Whitlatch RB (1998) Local control of recruitment in an epifaunal community and the consequences to colonization processes. Hydrobiologia 375-376:113-123

> Paine RT, Levin SA (1981) Intertidal landscapes: disturbance and the dynamics of pattern. Ecol Monogr 51:145-178

> Palmer MA, Allan JD, Butman CA (1996) Dispersal as a regional process affecting the local dynamics of marine and stream benthic invertebrates. Trends Ecol Evol 11:322-326

> Pascual M, Guichard F (2005) Criticality and disturbance in spatial ecological systems. Trends Ecol Evol 20:88-95

> Pascual M, Levin SA (1999) Spatial scaling in a benthic population model with density-dependent disturbance. Theor Popul Biol 56:106-122

Pearson TH, Rosenberg R (1978) Macrobenthic succession in relation to organic enrichment and pollution of the marine environment. Oceanogr Mar Biol Annu Rev 16:229-311

Pickett STA, White PS (eds) (1985) The ecology of natural disturbance and patch dynamics. Academic Press, Orlando

Pulliam HR (1996) Sources and sinks: empirical evidence and population consequences. In: Rhodes OE, Chesser RK, Smith MH (eds) Population dynamics in ecological space and time. University of Chicago Press, Chicago, p 45-69

Rhoads DC, McCall PL, Yingst JY (1978) Disturbance and production on the estuarine seafloor. Am Sci 66:577-586

> Rothschild BJ, Ault JS, Goulletquer P, Héral M (1994) Decline of the Chesapeake Bay oyster population: a century of habitat destruction and overfishing. Mar Ecol Prog Ser 111:29-39

Scheffer M, Carpenter S, Foley JA, Folke C, Walker B (2001) Catastrophic shifts in ecosystems. Nature 413:591-596

Sousa WP (1984) The role of disturbance in natural communities. Annu Rev Ecol Syst 15:353-391

Suding KN, Hobbs RJ (2009) Threshold models in restoration and conservation: a developing framework. Trends Ecol Evol 24:271-279

Tanner JE, Hughes TP, Connell JH (1996) The role of history in community dynamics: a modelling approach. Ecology $77: 108-117$ 
terHorst CP, Dudgeon SR (2009) Beyond the patch: disturbance affects species abundances in the surrounding community. J Exp Mar Biol Ecol 370:120-126

Thrush S, Dayton PK (2002) Disturbance to marine benthic habitats by trawling and dredging: implications for marine biodiversity. Annu Rev Ecol Syst 33:449-473

Thrush SF, Whitlatch RB (2001) Recovery dynamics in benthic communities: balancing detail with simplification. In: Reise K (ed) Ecological comparisons of sedimentary shores. Springer-Verlag, Berlin, p 297-316

Thrush SF, Pridmore RD, Hewitt JE, Cummings VJ (1991) Impact of ray feeding disturbances on sandflat macrobenthos: Do communities dominated by polychaetes or shellfish respond differently? Mar Ecol Prog Ser 69: 245-252

Thrush SF, Whitlatch RB, Pridmore RD, Hewitt JE, Cummings VJ, Wilkinson MR (1996) Scale-dependent recolonization: the role of sediment stability in a dynamic sandflat habitat. Ecology 77:2472-2487

Thrush SF, Hewitt JE, Funnell GA, Cummings VJ and others (2001) Fishing disturbance and marine biodiversity: the role of habitat structure in simple soft-sediment systems. Mar Ecol Prog Ser 223:277-286

Thrush SF, Hewitt JE, Cummings VJ, Ellis JI, Hatton C, Lohrer A, Norkko A (2004) Muddy waters: elevating sediment input to coastal and estuarine habitats. Front Ecol Environ 2:299-306

Thrush SF, Lundquist CJ, Hewitt JE (2005) Spatial and temporal scales of disturbance to the seafloor: a generalized framework for active habitat management. Am Fish Soc Symp 41:639-649

Thrush SF, Hewitt JE, Gibbs M, Lundquist C, Norkko A (2006) Functional role of large organisms in intertidal communities: community effects and ecosystem function. Ecosystems 9:1029-1040

Thrush SF, Halliday J, Hewitt JE, Lohrer AM (2008) Cumulative degradation in estuaries: the effects of habitat, loss fragmentation and community homogenization on resilience. Ecol Appl 18:12-21

Submitted: August 11, 2009; Accepted: February 16, 2010
Thrush SF, Hewitt JE, Dayton PK, Coco G and others (2009) Forecasting the limits of resilience: integrating empirical research with theory. Proc R Soc Lond B 276:3209-3217

Turner MG, Romme WH, Gardner RH, O'Neill RV, Kratz TK (1993) A revised concept of landscape equilibrium: disturbance and stability on scaled landscapes. Landsc Ecol 8: 213-227

- Turner SJ, Thrush SF, Hewitt JE, Cummings VJ, Funnell G (1999) Fishing impacts and the degradation or loss of habitat structure. Fish Manag Ecol 6:401-420

Whitlatch RB, Lohrer AM, Thrush SF, Pridmore RD, Hewitt JE, Cummings VJ, Zajac RN (1998) Scale-dependent benthic recolonization dynamics: life stage-based dispersal and demographic consequences. Hydrobiologia 375-376: $217-226$

Wiens JA, Schooley RL, Weeks RD Jr (1997) Patchy landscapes and animal movements: do beetles percolate? Oikos 78:257-264

Wilcox C, Cairns BJ, Possingham HP (2006) The role of habitat disturbance and recovery in metapopulation persistence. Ecology 87:855-863

With KA, Crist TO (1995) Critical thresholds in species' responses to landscape structure. Ecology 76:2446-2459

With KA, King AW (1999) Dispersal success on fractal landscapes: a consequence of lacunarity thresholds. Landscape Ecol 14:73-82

> With KA, King AW (2004) The effect of landscape structure on community self-organization and critical biodiversity. Ecol Model 179:349-366

> With KA, Gardner RH, Turner MG (1997) Landscape connectivity and population distributions in heterogeneous environments. Oikos 78:151-169

Zajac RN (2001) Organism-sediment relations at multiple spatial scales: implications for community structure and successional dynamics. In: Aller JY, Woodin SA, Aller RC (eds) Organism-sediment interactions. University of South Carolina Press, Columbia, p 119-139

Zajac RN (2008) Macrobenthic biodiversity and sea floor landscape structure. J Exp Mar Biol Ecol 366:198-203

Proofs received from author(s): June 25, 2010 